\title{
Functionally Graded Thermal Barrier Coatings with Improved Reflectivity and High-Temperature Capability
}

\author{
Robert Vassen ${ }^{1, a}$, Holger Kassner ${ }^{1, b}$, Alexandra Stuke ${ }^{1, c}$, Daniel Emil Mack ${ }^{1, d}$ \\ Maria Ophelia Jarligo ${ }^{1, \mathrm{e}}$ and Detlev Stöver ${ }^{1, \mathrm{f}}$ \\ ${ }^{1}$ Institute of Energy Research, Forschungszentrum Jülich $\mathrm{GmbH}, 52428$ Jülich, Germany \\ ar.vassen@fz-juelich.de, bh.kassner@fz-juelich.de, 'a.stuke@web.de, dd.e.mack@fz-juelich.de \\ em.o.jarligo@fz-juelich.de, ${ }^{\mathrm{f}} \mathrm{d}$. stoever@fz-juelich.de
}

\begin{abstract}
Keywords: Thermal barrier coating, gas turbines, ceramic top coats, plasma spraying, reflective coatings
\end{abstract}

\begin{abstract}
Conventional thermal barrier coating (TBC) systems consist of a duplex structure with a metallic bondcoat and a ceramic, heat isolative topcoat. In modern TBCs the ceramic topcoat is further divided into layers with different functions. One example is the double layer system in which conventional yttria stabilized zirconia (YSZ) is used as bottom and new materials as pyrochlores or perovskites are used as topcoat layers. These systems demonstrated an improved temperature capability compared to standard YSZ. Examples of such systems will be shown.

In modern gas turbines the increased temperatures and gas pressures lead to an increased fraction of radiative heat flow. Coatings with increased reflectivity can be used to avoid the direct heating of the metallic substrates by this radiation. An effective method to produce such coatings is suspension plasma spraying. These reflective coatings are deposited on top of the TBC system and will lead to a further grading and improved performance of the coating.
\end{abstract}

\section{Introduction}

Research efforts have been devoted in the development and manufacture of thermal barrier coating (TBC) systems of gas turbines to improve their operation temperature capabilities. Conventional TBC systems which usually consist of duplex structure with a metallic bondcoat and a ceramic heat isolative topcoat, have been further modified by either improving the properties of the ceramic topcoat or applying multi-layered coatings as in functionally gradient material (FGM) $[1,2,3,4]$. The concept of FGM TBC employs the deposition of a conventional ceramic topcoat material such as YSZ as the bottom layer and the top layer being the newly developed material.

Several pyrochlore and perovskite materials have shown promising physical and thermal properties for use as complementary upper layer of YSZ in the FGM TBC system. These materials exhibit lower thermal conductivity and higher thermal stability than YSZ $[2,5,6]$. However, when applied as lone ceramic topcoats, these materials tend to exhibit shorter thermal cycling endurance due to thermal mismatch in the TBC system as both substrate and bondcoat have relatively higher values of thermal expansion coefficients. To remedy this shortcoming, the candidate materials were tried as complementary topcoat for YSZ in double layer systems. Similar studies previously conducted have proven that this concept is indeed feasible $[7,8,9]$. Results of our study on FGM TBCs cycled at extremely high temperatures are presented in this paper.

Another approach to improve the performance of TBCs in modern gas turbines, deals with reducing the radiative heat flow brought about by increased temperatures and gas pressures during operation. An improved TBC therefore, should not only be resistant to thermal conduction but to radiation as well. The radiation transfer depends on optical properties described by the absorption and scattering coefficient and on the refractive index of the material [10]. Coatings with increased reflectivity can be used to avoid the direct heating of the metallic substrates by this radiation. YSZ on the other hand, the most popular TBC topcoat, tend to be nearly transparent to radiation in the near infrared (IR) range of wavelengths below $5 \mu \mathrm{m}$ where most of the radiation in the combustion 
chamber is being emitted $[11,12,13]$. However, the manner by which the coating is deposited can greatly influence its microstructure whereby pores and microcracks could be produced to enhance the optical properties of the coating; a modified FGM approach. An effective method to produce such coatings is through suspension plasma spraying (SPS) $[14,15]$. The SPS process often uses suspension of submicron powders injected into the plasma torch, where nano-particles dispersed in the suspension can also be directly injected into the torch for spraying [16]. Henceforth, methodologies and results on this investigation with YSZ as starting powder are also presented.

\section{Experimental Procedure}

Double Layer Coating Systems. About $150-\mu$ m-thick vacuum plasma-sprayed NiCoCrAlY bondcoat on disk-shaped nickel-base superalloy IN738 substrates with optimized thermal cycling sample geometry were used. The ceramic topcoats with total thickness of $300-500 \mu \mathrm{m}$ were produced by atmospheric plasma spraying (APS) using a Triplex I gun (Sulzer Metco). During the manufacture of the thermal cycling specimens, steel substrates were also coated for evaluation of the free-standing coating properties. The standard conditions for the deposition of the coatings are detailed in the previous publication [2]. The double layer systems consisted of an YSZ coating directly deposited on the bondcoat and a ceramic topcoat. The thickness of each coating was about half the total coating thickness. For comparison, the results of single layer YSZ coatings are also given. The YSZ powder used was a $7.8 \mathrm{wt} \%$ yttria stabilized zirconia powder (Metco $204 \mathrm{NS}$ ).

The ceramic top coats were pyrochlore $\mathrm{La}_{2} \mathrm{Zr}_{2} \mathrm{O}_{7}, \mathrm{Gd}_{2} \mathrm{Zr}_{2} \mathrm{O}_{7}$ and $\mathrm{La}_{2} \mathrm{Hf}_{2} \mathrm{O}_{7}$ and perovskites $\mathrm{BaMg}_{1 / 3} \mathrm{Ta}_{2 / 3} \mathrm{O}_{3}(\mathrm{BMT})$ and $\mathrm{SrZrO}_{3}$ synthesized through a solid state route following the procedures discussed in [2] and [5], respectively. The synthesized ceramic powders were then spray-dried to obtain dense powders of good flowability. Powders with sieved particle size between 30-80 $\mu \mathrm{m}$ for the pyrochlores and $45-125 \mu \mathrm{m}$ for the perovskites were used for plasma spraying. Particle size analysis by laser scattering (Fritsch analysette) determined the size distribution of the starting powders.

Reflective Coatings. YSZ coatings were deposited by suspension plasma spraying using a Triplex II gun (Sulzer Metco). Ethanol-based suspensions were injected into the plasma torch using a two-flux nozzle with controlled suspension (Psus $=200 \mathrm{kPa}$ ) and air pressure (Pair=50kPa). Optimized SPS parameters are detailed in [16]. Aside from ethanol, the suspensions were also composed of dispersants and $7-8 \mathrm{wt} \%$ YSZ powders with nanometric grains and different size distributions. Free-standing coatings and thermal cycling samples were also prepared and characterized in like manner as the double layer systems. All coatings were annealed in a furnace for 1 hour at $600^{\circ} \mathrm{C}$ to reduce the effect of oxygen loss in the YSZ-structure to the optical properties. APS systems were also prepared for comparison.

Evaluation of Properties. The open porosity including the pore distribution of free-standing coatings were characterized by means of mercury intrusion porosimetry. For the reflective coatings, both the hemispherical reflectance and the transmittance of free-standing coatings were determined in the wavelength range 0.3 to $2.5 \mu \mathrm{m}$ using a Perkin Elmer Lambda 950 IR-spectrometer. By means of an integration sphere the hemispherical radiation could be captured. The illumination of the coatings was directional $[13,15]$.

Finally, the thermal cycling tests on the different systems were conducted using a gas burner test facility operating with natural gas and oxygen. The detailed process description can be found elsewhere [17]. The systems consisting of the ceramic top layers and NiCoCrAlY bondcoat on a nickel base superalloy were subjected to various surface and substrate temperatures. Due to the low pressure of the heating gas, the coatings were not exposed to considerable thermal radiation. The surface temperature was measured with a pyrometer operating between the wavelengths $8-11.5 \mu \mathrm{m}$. The emissivity for YSZ was assumed to be one. Microstructures along the cross-section of the cycled samples were also determined by SEM. 


\section{Results}

Double Layer Coating Systems. Figure 1 summarizes the thermal cycling performance of the investigated systems. The lifetime range for standard YSZ coatings is also indicated for comparison [18]. Such YSZ coatings were found to fail at high temperatures due to thinning caused by subsequent spallation of individual splats [19].

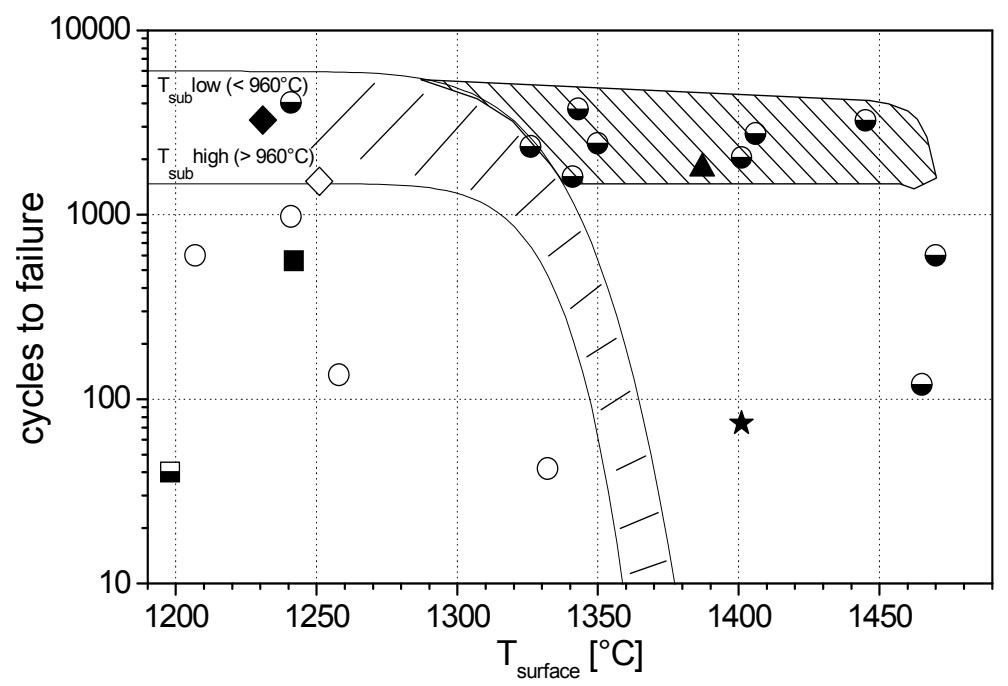

$\bigcirc$ single layer $\mathrm{La}_{2} \mathrm{Zr}_{2} \mathrm{O}_{7}$

double layer $\mathrm{YSZ} / \mathrm{La}_{2} \mathrm{Zr}_{2} \mathrm{O}_{7}$

$\Delta$ double layer $\mathrm{YSZ} / \mathrm{Gd}_{2} \mathrm{Zr}_{2} \mathrm{O}_{7}$

$\star$ double layer $\mathrm{YSZ} / \mathrm{La}_{2} \mathrm{Hf}_{2} \mathrm{O}_{7}$

$\square$ single layer BMT

double layer YSZ/BMT

$\diamond$ single layer $\mathrm{SrZrO}_{3}$

d double layer $\mathrm{YSZ} / \mathrm{SrZrO}_{3}$

lifetime range of standard YSZ

11 lifetime range of double

layer systems

Fig. 1. Cycles to failure of the investigated systems.

Single layer systems have cycling lifetime way below the standard YSZ coatings, while the double layer systems clearly show high cyclic endurance at high temperatures. The major failure mechanism for the pyrochloric double layer systems at surface temperatures below $1450^{\circ} \mathrm{C}$ is similar to the one observed for single layer YSZ coatings at similar bondcoat temperature, however, much lower $\left(<1350^{\circ} \mathrm{C}\right)$ surface temperature. A thermally grown oxide (TGO) is formed during thermal cycling [2]. This layer introduces additional stress near the interface within the TBC and leads to crack propagation. At a temperature of $1450^{\circ} \mathrm{C}$ the limit of the temperature capability of the double layer system seems to be reached. This is $100 \mathrm{~K}$ higher than the one of single layer YSZ coatings. A representative photograph and corresponding micrograph of the YSZ/ $\mathrm{La}_{2} \mathrm{Zr}_{2} \mathrm{O}_{7}$ double layer systems (Fig.2) reveal partial failure of the ceramic topcoat, as manifested by the spalled surface and presence of vertical cracks within the TBC.

For the perovskite topcoats, the cycling lifetime of the double layer systems have been greatly improved, compared to the single layer systems (Fig.1). BMT coatings have shorter thermal cycling lifetime owing to the low fracture toughness of the material [5]. Photographs and corresponding micrographs (Fig.3) reveal that the double layer made of perovskites fail at the bondcoat interface indicating that the failure is probably oxidation driven and not by limited temperature capability.

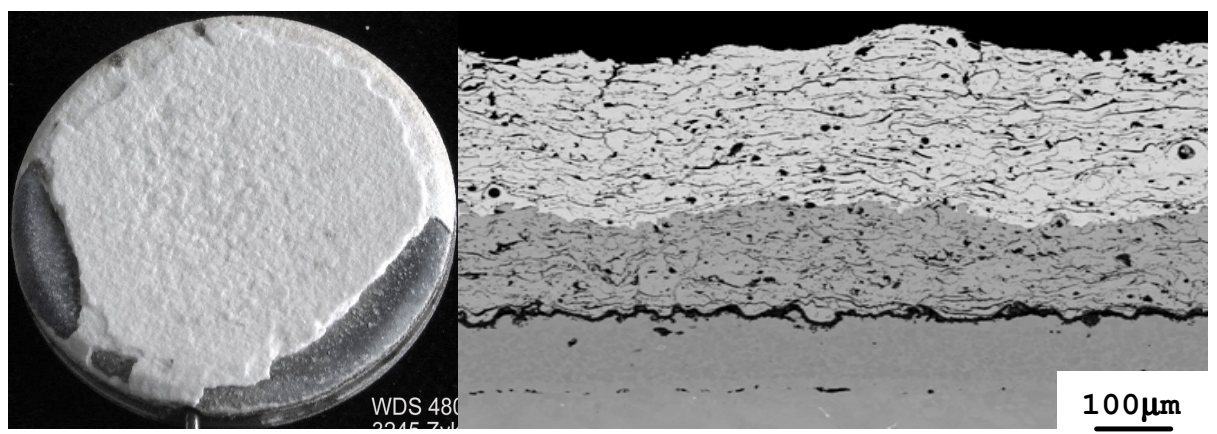

Fig. 2. Photograph and corresponding micrograph of the double layer $\mathrm{YSZ} / \mathrm{La}_{2} \mathrm{Zr}_{2} \mathrm{O}_{7}$ coating, after 3245 cycles at $1445^{\circ} \mathrm{C} / 1067^{\circ} \mathrm{C}$ surface/bondcoat temperature. 

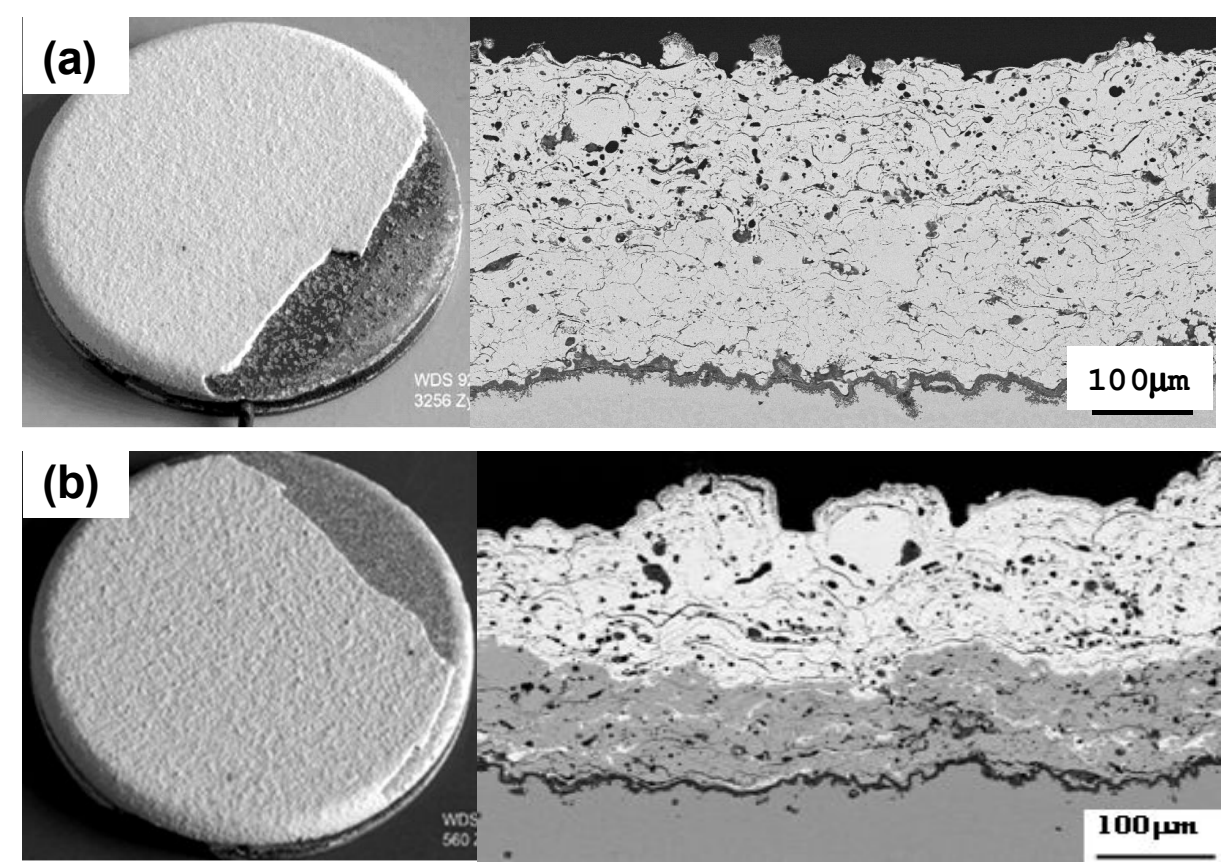

Fig. 3. Photographs and corresponding micrographs of the perovskite double layer (a) $\mathrm{YSZ}_{\mathrm{SrZrO}} \mathrm{S}$ after 3256 cycles at $1231^{\circ} \mathrm{C} / 974^{\circ} \mathrm{C}$ and (b) YSZ/BMT powder after 560 cycles at $1242^{\circ} \mathrm{C} / 1038^{\circ} \mathrm{C}$ surface/substrate temperature.

Reflective Coatings. Micrographs of the APS and SPS coatings are shown in Fig. 4 and Fig. 5 respectively. In contrast to the APS-coatings, the microstructure of all SPS-coatings is characterized by high crack density - vertical cracks, in particular. Small pores with size $\sim 0.2 \mu \mathrm{m}$ are also highly visible. Cycling lifetime of the APS-a coating $(\mathrm{P}=12 \%)$ at $1233^{\circ} \mathrm{C} / 1055^{\circ} \mathrm{C}$ surface/substrate temperature is 1712, a value lower than the SPS-b $(\mathrm{P}=29 \%)$ cycled for 1827 times at $1233^{\circ} \mathrm{C} / 1036^{\circ} \mathrm{C}$ surface/substrate temperature.

Optical Properties of the Sprayed Coatings. Fig. 6a shows the hemispherical reflectance spectra for the APS and SPS. The reflectance and the microstructure for both coating methods are clearly correlated. Coating reflectance increases with increasing porosity (from 9 to $40 \%$ ). The scattering coefficients for the coatings are shown in Fig. 6b. SPS coatings with high porosity display the highest scattering coefficient while dense APS coatings with low porosity display the lowest scattering coefficient. Comparison between the scattering coefficients of SPS and APS coatings show variations in proportion to the differences in the porosities of the coatings [15]. The scattering coefficients of SPS-a and SPS-b with difference in the porosity of about $6 \%$ show small variation, whereas the coatings APS-c $(\mathrm{P}=20 \%)$ with porosity much closer to SPS-a $(\mathrm{P}=23 \%)$ show by far lower scattering coefficient than the SPS-coatings. Other features like pore distribution and pore shape also affect the optical properties of the coatings.
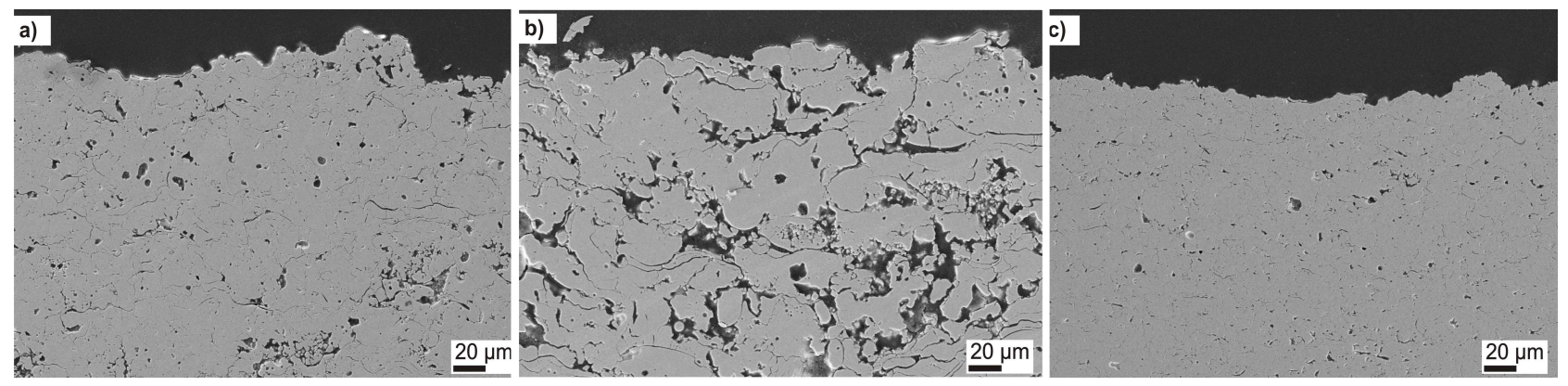

Fig. 4. Microstructures of APS Coatings: a) APS-a as reference coating, b) APS-b sprayed with large stand-off and c) APS-c from the dense powder. 


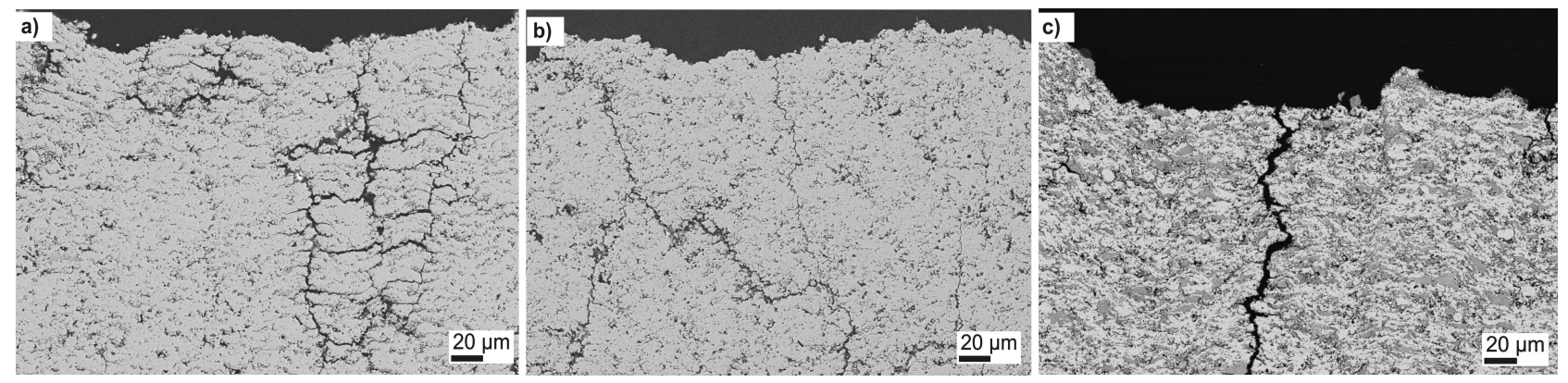

Fig. 5. Microstructures of SPS Coatings: a) SPS-a, b) SPS-b and c) SPS-c.
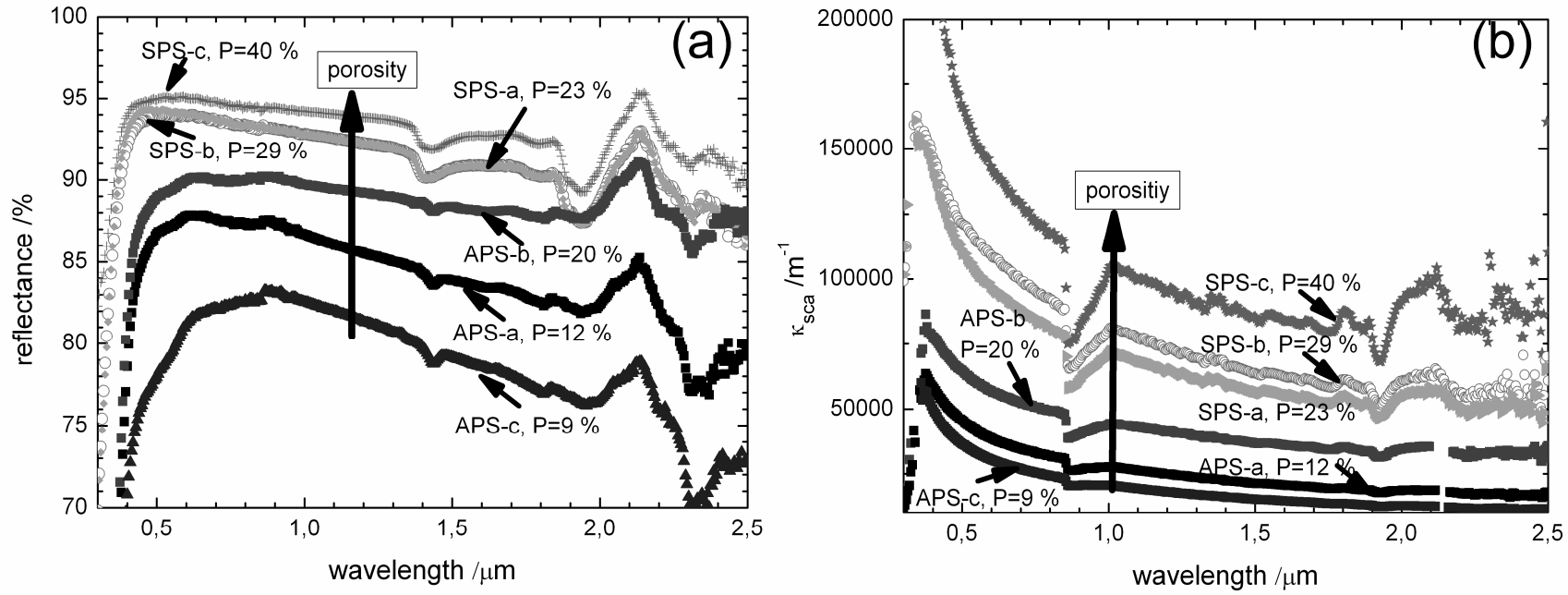

Fig. 6. Reflectance (a) and scattering coefficients (b) of the three APS and SPS coatings derived from IR integration sphere measurements according to [15].

\section{Summary}

TBC systems made from plasma spraying pyrochlores and perovskites in single layer and double layer systems have been tested for thermal cycling. Double layer systems have longer cycling lifetime compared to the single layer systems particularly $\mathrm{La}_{2} \mathrm{Zr}_{2} \mathrm{O}_{7}$ and $\mathrm{Gd}_{2} \mathrm{Zr}_{2} \mathrm{O}_{7}$ pyrochlores and $\mathrm{SrZrO}_{3}$ perovskite, which performed similar or better than the standard $\mathrm{YSZ}$ coatings. On the other hand, TBCs with increased porosities through SPS yielded good cycling lifetime and improved screening of the IR-radiation than the conventional APS coatings. These FGM coatings therefore, have the capability of allowing greater efficiency in gas turbine operations at high temperatures.

\section{References}

[1] J.H. Kim , M.C. Kim and C.G. Park: Surf. Coat. Technol. Vol. 168 (2003), p. 275-280

[2] R. Vaßen, F. Traeger and D. Stöver: Int. J. Appl. Ceram. Technol. Vol. 1 [4] (2004), p. 351-61

[3] X.Q. Cao, R. Vassen, F. Tietz and D. Stoever: J. Euro. Ceram. Soc. Vol. 26 (2006), p. 247-251

[4] S. Rangaraj and K. Kokini: Acta Mater. Vol. 51 (2003), p. 251-267

[5] W. Ma, M. O. Jarligo, D. E. Mack, D. Pitzer, J. Malzbender, R. Vaßen and D. Stöver: submitted to the Journal of Thermal Spray Technologies (2008)

[6] R. Vassen, X. Cao, F. Tietz; Basu and D. Stöver: J. Am. Ceram. Soc. Vol. 83 (1999) p. 2023-28

[7] R. Vaßen, G. Pracht and D. Stöver: in Proceedings of the 2002 International Thermal Spray Conference. 
[8] R. Vaßen, G. Barbezat and D.Stöver, in: Materials for Advanced Power Engineering, edited by J. Lecomte-Becker, M. Carton, F. Schubert, P.J. Ennis, (2002).

[9] R. Vaßen, X.Q. Cao and D. Stöver: in Ceramic Engineering and Science Proceedings, (2001).

[10]C. M. Spuckler: in Proceedings of the 28th International Cocoa Beach Conference and Exposition on Advanced Ceramics and Composites, (2008)

[11]V. Debout, F. Enguehard, A. Meillot, P. Abélard, E. Bruneton and P. Fauchais: in Proceedings of the 2006 International Thermal Spray Conference

[12]J.I. Eldridge, C.M. Spuckler, K.W. Street, J.R. Markham: Ceram. Eng. Sci. Proc. Vol. 23(2002), p. 7417-429

[13]A. Stuke, R. Carius, J.-L. Marquéz, G Mauer, M. Schulte, D. Sebold, R. Vaßen and D. Stöver: 31st International Cocoa Beach Conference and Exposition on Advanced Ceramics and Composites, Ceramic Engineering Science Proceeding (2007)

[14]H. Kaßner, A. Stuke, R. Vaßen and D. Stöver: in Proceedings of the 2008 International Thermal Spray Conference.

[15]A. Stuke, H. Kaßner, J.-L. Marqués, R. Carius, R. Vaßen and D. Stöver: submitted to the International Journal of Applied Ceramics Technology (2008)

[16]H. Kassner, R. Siegert, D. Hathiramani, R. Vaßen and D. Stöver: J. Therm. Spray Technol. Vol. 17 (2008), p.115

[17]F. Traeger, R. Vassen, K-H. Rauwald and D. Stöver: Adv. Eng. Mater. Vol. 5 (2003), p. 429-33

[18]F. Traeger, M. Ahrens, R. Vaßen, D. Stöver: Mater. Sci. Eng. A. Vol. 358 (2003), p. 255-65

[19]R. Vaßen, F. Traeger and D. Stöver: Proceedings of the 2003 International Thermal Spray Conference, $p$. 1573-1582. 